\title{
Increased presentations to emergency departments for asthma associated with rye grass pollen season in inland NSW
}

\author{
Timothy J. Hayden ${ }^{\mathrm{A}}$ and David J. Muscatello ${ }^{\mathrm{B}, \mathrm{C}}$ \\ ${ }^{\mathrm{A}}$ NSW Public Health Officer Training Program, \\ NSW Department of Health \\ ${ }^{\mathrm{B}}$ Emergency Department Surveillance Unit, Centre for \\ Epidemiology and Research, NSW Department of Health \\ ${ }^{\mathrm{C}}$ Corresponding author.Email: dmusc@doh.health.nsw.gov.au
}

\begin{abstract}
Aim: This study measured the frequency and geographical extent of peaks in asthma presentations to emergency departments in inland NSW; it assessed the characteristics of patients who presented at peak presentation times during the rye grass pollination season (October-November) and at other times of the year. Methods: Data describing over 13 years of daily emergency department presentations with a provisional diagnosis of asthma at nine inland NSW base hospitals were assembled. Days of counts in the top 0.1 percentile for each emergency department were classified as peak asthma count days. Results: While the rye grass pollen season accounts for only $17 \%$ of days in the year, $53 \%$ of peak asthma count days fell within that period. Patients aged over 14 years represented $74 \%$ of visits on peak asthma count days during the pollen season and $50 \%$ on peak days at other times of the year. Discussion: Under the right climatic conditions, rye grass pollen may be responsible for presentations for acute asthma to emergency departments in inland NSW.
\end{abstract}

Asthma is an important public health problem in Australia, with over 2 million people suffering from the condition in 2005. This represents one of the highest prevalences of asthma in the world. ${ }^{1}$ While asthma is a chronic condition, people with asthma can have acute exacerbations, or attacks, which can restrict their breathing sufficiently to cause them to present to hospital for emergency treatment, and which can on occasion be fatal. ${ }^{2}$ Triggers for acute asthma attacks vary between individuals but include exposure to indoor and outdoor allergens, air pollutants, respiratory tract infections, exercise, weather changes, foods, additives, drugs and emotional stress. ${ }^{3}$

Hospital admissions for asthma in Australia are more frequent in remote areas and in socioeconomically disadvantaged areas than in major cities. ${ }^{1}$ Children have higher rates of emergency department visits and hospital admissions for asthma than adults, particularly during February and May in Australia, while adults have higher rates during the winter months. In regional New South Wales (NSW) marked increases in the incidence of acute asthma exacerbations have been reported in late spring and early summer. ${ }^{4}$

Other environmental factors implicated in these epidemics include sudden changes in temperature, high rainfall and humidity, viral infections, increased ozone levels, smallparticle atmospheric fungal spores and grass pollens. ${ }^{4,5}$ Previous studies have found a positive correlation between allergy to annual rye grass pollen and spring asthma exacerbation. ${ }^{4,6-8}$ A case-control study conducted in six inland rural towns in NSW showed a close temporal association with thunderstorms during late spring and early summer, ruptured rye grass pollen grains and the onset of an asthma epidemic. ${ }^{9}$

The timing of rye grass pollen activity varies from state to state; however, in south-eastern Australia it is generally from late September to the end of December, with seasonal peaks around mid-October to early December. ${ }^{10}$

We conducted a descriptive epidemiological study to assess the frequency and geographical range of unusually large daily counts of asthma presentations to emergency departments in regional NSW and their relation to the rye grass pollination season.

\section{Methods}

Data were obtained from the NSW Department of Health centralised Emergency Department Data Collection, which currently contains records of visits to emergency departments in over 90 hospitals in NSW. Depending on the patient management software and coding systems in use, asthma visits were identified from codes of the International Classification of Diseases (ICD) versions 9 and $10^{11,12}$ and the Standardised Nomenclature of Medicine Clinical Terminology (SNOMED CT) ${ }^{13}$ The ICD-9 code used was 493, and the ICD-10 codes used were J45 and J46. 
Table 1. Minimum and maximum counts of daily asthma presentations for peak asthma count days and overall median count at nine inland hospitals in NSW for the period July 1996-December 2009

\begin{tabular}{lccc}
\hline $\begin{array}{l}\text { Hospital emergency } \\
\text { department }\end{array}$ & Asthma presentations for peak asthma count days & Median count \\
\cline { 2 - 4 } & $\begin{array}{c}\text { Minimum } \\
n\end{array}$ & $n$ & $n$ \\
\hline Albury & 10 & 21 & 1 \\
Wagga Wagga & 36 & 164 & 1 \\
Griffith & 6 & 9 & 1 \\
Dubbo & 7 & 23 & 1 \\
Orange & 7 & 11 & 1 \\
Broken Hill & 6 & 8 & 1 \\
Goulburn & 4 & 8 & 1 \\
Bathurst & 5 & 16 & 1 \\
Tamworth & 11 & 20 & 1 \\
\hline
\end{tabular}

Peak asthma count days were defined as daily counts of asthma visits which were in the top 0.1 percentile of asthma visit counts at each hospital.

Daily presentations to emergency departments resulting in a provisional diagnosis of asthma between 1 July 1996 and 31 December 2009 were recorded at nine large regional inland NSW hospitals in Tamworth, Bathurst, Orange, Albury, Griffith, Wagga Wagga, Dubbo, Goulburn and Broken Hill. Peak asthma count days at each emergency department were considered those on which daily counts fell within the upper 0.1 percentile of all daily counts for the emergency department. Peak asthma count days were further classified into those that occurred during the period recognised as being the rye grass pollination season, 15 October-30 November, ${ }^{10}$ and those occurring on other days of the year.

We further classified individual emergency department visit records into those on a peak count day during the rye grass pollination season, those on a peak count day at other times of the year and all remaining days. To assess variation in demographics, urgency and severity, we calculated the frequency distribution of asthma emergency department visits in each category by age, sex, arrival mode, triage category and mode of separation.

\section{Results}

Between 1 July 1996 and 31 December 2009, there were 45215 presentations to the nine selected emergency departments assigned a provisional diagnosis of asthma. The median daily count for each hospital emergency department was one. A total of 78 peak asthma count days were identified in all emergency departments during this time. The peak asthma counts ranged from 36-164 in Wagga Wagga to 6-8 in Broken Hill (Table 1). The largest sudden epidemic at any emergency department in the study occurred on 30 and 31 October 1997 at Wagga Wagga Base Hospital, where, over a 24-hour period, 215 visits were assigned a provisional diagnosis of asthma. The second largest event occurred at the same emergency department at around the same time in 1996, with 84 visits for asthma over 48 hours.
Figure 1 shows the distribution of peak asthma count days throughout the year, showing clustering of these days during the rye grass pollination period. Even though this period comprises only $17 \%$ of days of the year, it contains $53 \%$ of the peak asthma count days identified. Every peak asthma count day at Wagga Wagga and Albury base hospitals occurred during this period; however, all peak asthma count days at Broken Hill Base Hospital fell outside the pollination period.

Table 2 compares the characteristics of patients presenting on peak asthma count days during the rye grass pollination season with those presenting on other peak asthma count days and all remaining days. Patients presenting on peak asthma count days during the pollen season tended to be older, 79\% being aged 15 years or over, compared with $50 \%$ on other peak asthma count days and $54 \%$ on all other days. The proportion of males on peak asthma count days was slightly greater during the pollen season (52\%) than at other times of the year (47\%) and on all other days (49\%). Ambulance arrivals were less common on peak asthma count days during the rye grass season (only $6 \%$ arriving by ambulance compared with $13 \%$ on both peak asthma count days at other times of the year and on all other days). Lower urgency triage categories were assigned to a greater proportion of presentations on peak asthma count days during the pollen season (44\%) than on other peak asthma count days (36\%) and all other days (38\%). The proportion of patients admitted was markedly lower on rye grass season peak asthma count days (16\%) than on peak asthma count days at other times of the year (32\%) and other days $(27 \%)$.

\section{Discussion}

We found a strong seasonal relationship between sudden asthma epidemics and the rye grass pollen season in regional inland NSW (Tamworth, Bathurst, Orange, Albury, Griffith, Wagga Wagga, Dubbo, Goulburn and 


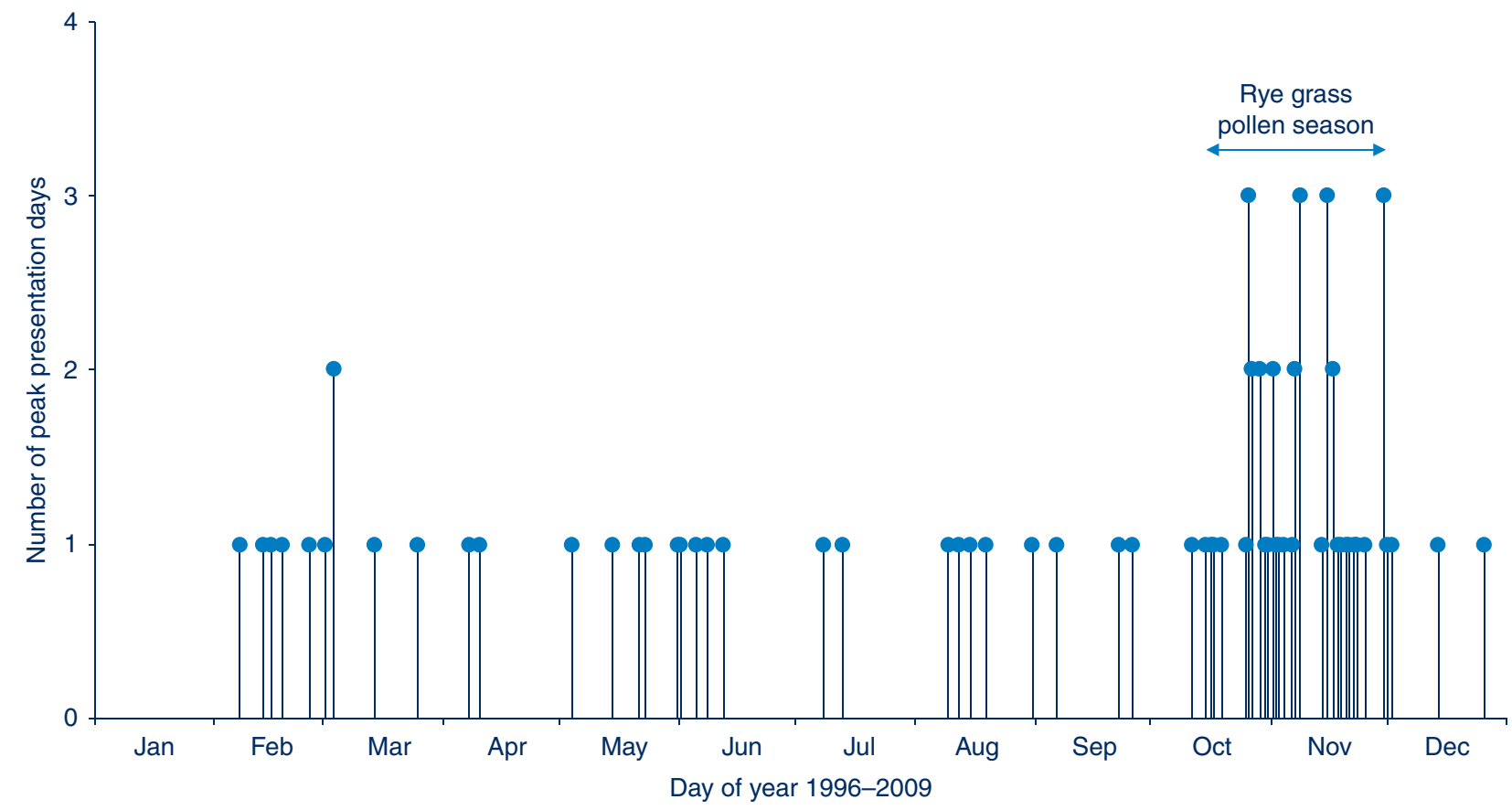

Figure 1. Peak asthma presentation days occurring on any day of the year at nine inland NSW emergency departments for the period 1996-2009.

Peak asthma count days were defined as daily counts of asthma visits which were in the top 0.1 percentile of asthma visit counts at each hospital.

Table 2. Characteristics of patients presenting on peak asthma count days during rye grass pollen season, peak count days at other times of the year, and all other days, for nine inland NSW emergency departments, 30 June 1996-31 December 2009

\begin{tabular}{|c|c|c|c|c|c|c|c|}
\hline \multirow[t]{3}{*}{ Group } & \multirow[t]{3}{*}{ Subgroup } & \multicolumn{6}{|c|}{ Asthma presentations } \\
\hline & & \multicolumn{2}{|c|}{$\begin{array}{l}\text { Peak count days, } \\
\text { pollen season }\end{array}$} & \multicolumn{2}{|c|}{$\begin{array}{l}\text { Peak count days, } \\
\text { non-pollen season }\end{array}$} & \multicolumn{2}{|c|}{ Other days } \\
\hline & & $n$ & $\%(95 \% \mathrm{Cl})$ & $n$ & $\%(95 \% \mathrm{Cl})$ & $n$ & $\%(95 \% \mathrm{Cl})$ \\
\hline \multirow[t]{2}{*}{ Sex } & Male & 366 & $52.3(48.6-66.0)$ & 91 & $47.4(40.3-54.5)$ & 21896 & $49.4(48.9-49.9)$ \\
\hline & Female & 334 & $47.7(44.0-51.4)$ & 101 & $52.6(45.5-55.7)$ & 22418 & $50.6(50.1-51.0)$ \\
\hline \multirow{6}{*}{$\begin{array}{l}\text { Age group } \\
\text { (years) }\end{array}$} & $0-4$ & 36 & $5.1 \quad(3.5-6.8)$ & 44 & $22.9(13.2-24.3)$ & 10085 & $22.8(22.4-23.1)$ \\
\hline & $5-14$ & 112 & $16.0(13.3-18.7)$ & 52 & $27.1(20.8-33.4)$ & 10104 & $22.8(22.4-23.2)$ \\
\hline & $15-24$ & 176 & $25.1(21.9-28.4)$ & 30 & $15.6(10.5-20.8)$ & 7046 & $15.9(15.6-16.2)$ \\
\hline & $25-34$ & 154 & $22.0(18.9-25.1)$ & 19 & $9.9 \quad(5.7-14.1)$ & 4652 & $10.5(10.2-10.8)$ \\
\hline & $35-64$ & 185 & $26.4(23.2-29.7)$ & 31 & $16.2(10.9-21.4)$ & 9476 & $21.4(21.0-21.8)$ \\
\hline & $65+$ & 37 & $5.3 \quad(3.6-6.9)$ & 16 & $8.3 \quad(4.4-12.2)$ & 2959 & $6.7 \quad(6.3-6.9)$ \\
\hline \multirow[t]{2}{*}{ Arrival mode } & Ambulance & 39 & $5.6 \quad(3.9-7.3)$ & 24 & $12.5(7.8-17.2)$ & 5768 & $13.0(12.7-13.3)$ \\
\hline & Private vehicle & 661 & $94.4(92.7-96.1)$ & 168 & $87.5(82.8-92.2)$ & 38555 & $87.0(86.7-87.3)$ \\
\hline \multirow[t]{3}{*}{ Triage category } & High (category 1-2) & 63 & $9.0 \quad(6.9-11.1)$ & 15 & $7.8 \quad(4.0-11.6)$ & 4767 & $10.8(10.5-11.0)$ \\
\hline & Medium (category 3) & 330 & $47.1(43.4-50.8)$ & 109 & $56.8(49.8-63.8)$ & 22491 & $50.7(50.3-51.2)$ \\
\hline & Low (category 4-5) & 307 & $43.9(40.2-47.5)$ & 68 & $35.4(28.7-42.2)$ & 17056 & $38.5(38.0-38.9)$ \\
\hline \multirow[t]{2}{*}{ Departure status } & Admitted & 113 & $16.1(13.4-18.9)$ & 62 & $32.3(25.7-38.9)$ & 11761 & $26.5(26.1-26.9)$ \\
\hline & $\begin{array}{l}\text { Departed from } \\
\text { the emergency } \\
\text { department }\end{array}$ & 587 & $83.9(81.1-86.6)$ & 130 & $67.7(61.1-74.3)$ & 32562 & $73.5(73.1-73.9)$ \\
\hline
\end{tabular}


Broken Hill). Increases in emergency department visits were more marked among adults than children during these events, and the severity appeared to be lower than usual, as indicated by lower triage urgency and less frequent admissions. This may, however, reflect lower clinical acuity in adults with acute asthma than in children or saturation of resources in regional hospitals.

A limitation of this study was that we had access only to emergency department visit information. Some people with asthma may have sought general practice care, while others may have managed their illness at home, and ambulance services may not have been able to respond to the unusually large number of presentations, affecting the arrival mode. The systematically recorded, extensive emergency department data do, however, provide a snapshot of trends in asthma occurrence. Addition of information on presentations other than to emergency departments is likely to have increased the numbers.

While thunderstorm activity has been emphasised in some studies as a cause of sudden asthma epidemics, ${ }^{6,8,9}$ environmental factors associated with thunderstorms cannot be considered in isolation. There is evidence that the conditions generated by a thunderstorm facilitate the hydration of pollen grains, leading to fragmentation and generating inhalable allergenic aerosols..$^{9}$ This hypothesis suggests that thunderstorm activity is not a direct cause but a mechanism for dispersing the allergens within the pollen.

The Australian Bureau of Meteorology collects information on thunderstorms by recording whether thunder is heard at the relevant site. The Bureau also publishes monthly 'significant weather summaries', which describe storm activity at certain locations and dates. ${ }^{14}$ Although we intended to investigate the correlation between thunderstorm activity and asthma, data on thunderstorms at specific locations were lacking, and the available data were insufficient for a correlational analysis. While we were unable to include direct measures of rye grass pollen and thunderstorms in our study, we nevertheless found that the greatest occurrence of high count asthma events occurred during the rye grass pollen season. Our findings suggest the need for better understanding of the potential synergy between rye grass pollination and thunderstorm activity in asthma epidemics.

In NSW, rye grass is found mainly in crops and pastures and is especially well adapted to most soil types in the southern Australian wheat belt. ${ }^{15}$ In our study, we found peak asthma presentations during the rye grass pollen season at all emergency departments studied except for Broken Hill, where there is limited rainfall and soil types that are not conducive to annual rye grass growth. ${ }^{15}$

Seasonal aeroallergens vary by region and geography, and rye grass pollen counts can vary widely from one season to the next, however the pollen season usually occurs during late spring and early summer. ${ }^{8}$ Schappi et al found that the amount of seasonal grass pollen directly correlated with the rainfall during the preceding 12 months. ${ }^{16}$ Seasonal changes may also be affected by climate change, increasing allergen release through earlier seasonal bud bursts. ${ }^{4}$ Davis and Walsh identified significant increases in thunderstorm activity in south-eastern Australia in the period 1941-2004, which may also be linked to the effects of climate change. ${ }^{17}$ Taylor et al highlighted a fall in the prevalence of asthma that coincided with a reduction in atmospheric pollen caused by the low average rainfall experienced since the mid-1990s across south-eastern Australia. $^{18}$

\section{Conclusion}

Using data for 13 years covering a wide geographical area, we found evidence that rye grass pollination may be responsible for a greater burden of acute asthma presentations to hospitals in inland NSW, particularly in adults, than previously recognised. Sudden asthma epidemics have the potential to overload primary health care facilities and may have a social impact on the community. This study provides support for the development of an early warning system to alert residents of inland NSW to the risk of asthma during the rye grass pollen season. Further research is required to determine whether thunderstorms are a necessary condition for epidemic asthma of this kind or whether they are a catalyst for stronger than usual, sudden epidemics, and whether other specific weather conditions could be responsible on other days when these events occur. Collaboration is needed in the fields of public health, health care, climate and agriculture to ensure good quality, complete meteorological, pollen, grass distribution and health care information. This will allow a clearer understanding of the role of each of these factors in generating asthma events and in determining which individuals and communities are at risk.

\section{Acknowledgments}

The authors would like to acknowledge the participants of a writing workshop led by Elisabeth Heseltine and sponsored by the NSW Department of Health for their contributions to the development of this article.

\section{References}

1. Australian Centre for Asthma Monitoring 2008. Asthma in Australia 2008. AIHW Asthma Series no. 3 Cat. no. ACM 14. Canberra: AIHW.

2. Forbes L, Harvey S, Newson R, Jarvis D, Luczynska C, Price J et al. Risk factors for accident and emergency (A\&E) attendance for asthma in inner city children. Thorax 2007; 62: 855-60. doi:10.1136/thx.2006.058362

3. Rodrigo GJ, Rodrigo C, Hall JB. Acute asthma in adults: a review. Chest 2004; 125: 1081-102. doi:10.1378/chest. 125.3.1081 
4. Girgis ST, Marks GB, Downs SH, Kolbe A, Car GN, Paton R. Thunderstorm-associated asthma in an inland town in southeastern Australia. Who is at risk? Eur Respir J 2000; 16: 3-8. doi:10.1034/j.1399-3003.2000.16a02.x

5. Nasser SM, Pulimood TB. Allergens and thunderstorm asthma. Curr Allergy Asthma Rep 2009; 9: 384-90. doi:10.1007/s11882009-0056-8

6. Bellomo R, Gigliotti P, Treloar A, Holmes P, Suphioglu C, Singh MB et al. Two consecutive thunderstorm associated epidemics of asthma in the city of Melbourne. The possible role of rye grass pollen. Med J Aust 1992; 156: 834-7.

7. Waters J, Corbett S, Gibson P, Hensley M, Wlodarczyk J. Epidemic asthma surveillance in the New England region 1990-1992. N S W Public Health Bull 1993; 4: 100-1. doi:10.1071/NB93049

8. Davidson AC, Emberlin J, Cook AD, Venables KM. A major outbreak of asthma associated with a thunderstorm: experience of accident and emergency departments and patients' characteristics. BMJ 1996; 312: 601-4.

9. Marks GB, Colquhoun JR, Girgis ST, Koski MH, Treloar AB, Hansen $\mathrm{P}$ et al. Thunderstorm outflows preceding epidemics of asthma during spring and summer. Thorax 2001; 56: 468-71. doi:10.1136/thorax.56.6.468

10. Ragg M. Australian pollen calendar. CSIRO Australia. Available from: http://www.dar.csiro.au/airwatch/docs/Pollen Calendar.pdf (Cited 4 January 2010.)

11. National Coding Centre. Australian version of the International Classification of Diseases. 9th revision, clinical modification (ICD-9-CM). Sydney: University of Sydney; 1996.
12. National Centre for Classification in Health. International Statistical Classification of Diseases and Related Health Problems, 10th Revision, Australian Modification (ICD-10-AM) (5th ed). Sydney: National Centre for Classification in Health; 2006.

13. International Health Terminology Standards Development Organisation. SNOMED-CT. Available from: http://www. ihtsdo.org/snomed-ct/ (Cited 1 April 2010.)

14. Australian Bureau of Meteorology. Monthly significant weather summaries. Available from: http://reg.bom.gov.au/inside/ services_policy/public/sigwxsum/sigwmenu.shtml (Cited 22 January 2010.)

15. NSW Department of Primary Industries. Best management practices for dryland cropping systems - Annual ryegrass (Lolium rigidum). Murrumbidgee Catchment Management Authority; 2008.

16. Schappi GF, Taylor PE, Kenrick J, Staff IA, Suphioglu C. Predicting the grass pollen count from meteorological data with regard to estimating the severity of hayfever symptoms in Melbourne (Australia). Aerobiologia 1998; 14: 29-37. doi:10.1007/BF02694592

17. Davis S, Walsh KJE. Southeast Australian thunderstorms: are they increasing in frequency? Aust Met Mag 2008; 57: 1-11.

18. Taylor PE, Jacobson KW, House JM, Glovsky MM. Links between pollen, atopy and the asthma epidemic. Int Arch Allergy Immunol 2007; 144: 162-70. doi:10.1159/000103230 